\title{
W.L. van der Merwe daag die dood uit
}

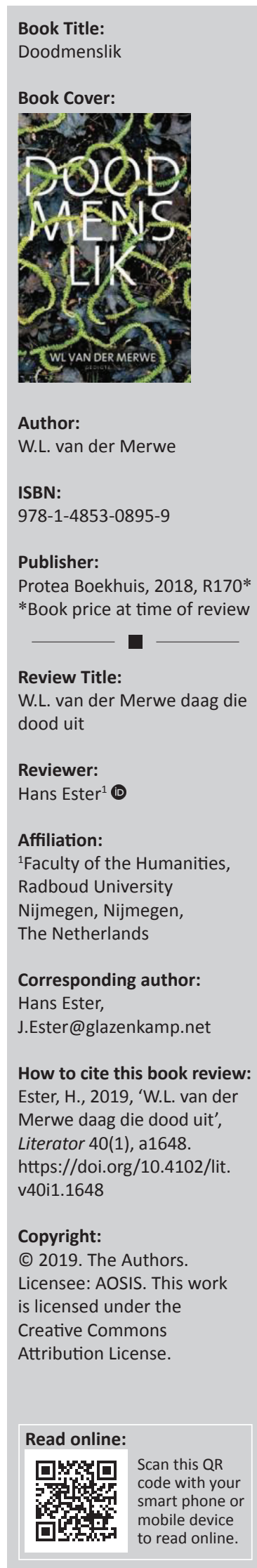

Is dit aangenaam of selfs plesierig om gedigte te lees? Miskien is hierdie vraag verkeerd en gaan dit by die lees van poësie in die eerste plek om ander emosies. Wanneer die leser 'n gedigteks begryp, is hierdie oorwinning van die vreemdheid van die teks ' $n$ bevestiging van die geestelike vermoëns van die leser. Helaas, ook hierdie ydelheid is nie die rede waarom 'n mens poësie lees nie. Die wesenlike leesmotivering is ' $n$ vorm van nuuskierigheid na die bron van die verwondering as gevolg van die poëtiese spel met die taal. Poësie ontdek kwaliteite van die taal wat ' $n$ mens nie van die oppervlak van die woorde van elke dag kan aflees nie.

Gedigte lees, is deelname aan die edel spel van die taal, soos Elisabeth Eybers dit geformuleer het. Edel, omdat die taal in hoogstaande gedigte diep gerespekteer word en as medium van singewing funksioneer.

W.L. van der Merwe dra sy verwondering oor die taal aan die leser oor. Sy ernstige taalspel is vir hom die pad na die lewe, nadat die dood die lewe oorval en vermink het. In die gedigte uit hierdie bundel met die kragtige titel, Doodmenslik, is dit keer op keer die dood wat die digter verarm en tot 'n weerwoord dwing. Die verarming deur die dood is intensivering van die lewenservaring. Die digter is 'n beskeie Orfeus, omdat hy weet dat sy skeppende vermoëns beperk is. Nogtans veg hy terug, met die skerpste wapen wat hy besit: die taal. Die woorde van ontsteltenis en rou voeg hulle saam tot 'n nuwe verband, tot verbondenheid wat uitstyg bo ewige afskeid. Voorbeelde van hierdie skeppende verband is die gedigte 'begrafnis', 'grafsteen' en 'die kleur van grys'. Die mees aangrypende is die gedig 'Fuga in swart' wat op die beroemde 'Todesfuge' van die Duitstalige digter Paul Celan voortbou.

Die digter soek na elemente in die werklike wêreld om draer van die oorstyging van die wette van lewe en dood te wees. Vir hierdie verlange bied voëls hulle as simboliese wesens aan. Voëls en ander elemente uit die natuur soos bome, neem die betekenis van verheffing bo die tasbare aan. In hulle sigbare verbeelding van betekenis, is hulle troostend. Met hierdie simbolisering korrespondeer die noodsaak om bestaande voorstellings van God teen die lig te hou, om hulle waarheid en waarde te bepaal. Indringende voorbeelde hiervan is die gedigte 'my godsbegrip', 'en toe was daar God' en die gedig 'reisadvies vir God', waarin God aanbeveel word om vanuit die idilliese gebied van die Duitse rivier Mosel, na Auschwitz te reis.

Vir die digter was (moontlik: is) Nederland 'n nuwe, bekende en sekerlik ook vreemde land. Terwyl Nederland vir Elisabeth Eybers altyd die bedreigende land met sy Nederlandse taal gebly het, waarteen sy haar met poësie in Afrikaans verdedig, is Van der Merwe nuuskierig. Die digter skryf oor Nederlandse eienaardighede vanuit die behoefte om sy ervarings te verstaan. Tot hierdie besondere verskynsels behoort die kommersiële gebruik van seksualiteit, in die besonder die vertoon van geslagsgemeenskap op die verhoog van 'n seksteater, of die skynbare intimiteit met 'n naakte vrou in 'n sogenaamde peep-show in Amsterdam. Dit is beslis nie die enigste verskynsels nie. Die digter laat ook die natuur en die landskap van Nederland toe om húlle besonderheid mee te deel. Van die raakvlak met die Nederlandse natuur, getuig die diep simboliese foto op die omslag van Van der Merwe se bundel, Rangskik groen takkies op verlepte blare, met die verwysing na die eiland Terschelling. Die mooiste uitdrukking van vereenselwiging, is seker die gedig 'de kleur van grijs', wat in Nederlands geskryf is.

Die dooie blare saam met die opdrag van die bundel, 'Vir Lettie, 16-09-1956 - 15-10-2017', gee vanaf die begin aan dat hierdie gedigte met verganklikheid en met dood verbind is. Die beeld van Nederland het ook deel aan die kleur wat die lewe oorheers: grys. Sterker as die opstandige Eybers, naamlik vanuit 'n houding van gelatenheid, assosieer Van der Merwe sy nuwe land, Nederland, en ook die vreeswekkende Noordzee met 'n toon van bewuste aanvaarding van die alomteenwoordige grysheid.

Om hierdie gedigte te lees, is 'n groot verryking. Ook wanneer die klaende, 'grys' grondtoon oorduidelik is en die twisgesprek met die dood invoeling en inspanning van die leser verlang, word die leser met lewensverdieping en wysheid beloon. 